\title{
Development of an Interactive Learning Resource in Engineering Mechanics
}

\author{
Terry Berreen \\ Monash University, Australia
}

\begin{abstract}
.
Helping students to progressively take greater control of their own learning means that in the early years of an undergraduate course a careful selection of learning resources must be made available and some guidance through these resources is necessary. This paper deals with providing such students with interactive computer material on engineering mechanics. This material can be used in either study mode or lecture mode and contains various exercises, animations and quantitatively correct simulations. The combining of these with other learning resources such as mathematical packages and laboratory work is considered.
\end{abstract}

\section{Introduction}

There would appear, from recent reviews of engineering education in the USA ${ }^{1}$ and in Australia $^{2}$ that there is strong impetus towards a broadening of engineering courses and a striving to make students more central in the whole educational process. Coupled with these directions is a highlighting of longlife learning aspects so that students progressively take greater control of their learning. This means that as important as the technical skills is the obtaining of the learning skills to ensure a strong relationship with ever changing disciplines. This paper in considering teaching and learning resources in engineering mechanics concentrates on the development of computer material incorporating qualitatively precise simulation, animation and graphing. The developments are just not restricted to engineering mechanics, they are relevant to all engineering subjects and in fact to teaching and learning resources in general. A particular interactive teaching and learning resource, CD-Engineering Mechanics by Berreen \& Alfredson ${ }^{3}$ is described.

\section{Learning Resources}

The range of learning resources available to students has increased in the past decade, very much related to advances in information technology. These resources now include lectures, problem-based learning, tutorials, problem classes, laboratory work, the world wide web, textbooks, lecture notes, subject specific computer packages, mathematical packages etc. There has been a major increase in recent years in the learning material, including lecture notes, for many engineering courses on the web. Some of these are just lecture notes, using the web as a distributor of university course materials. These may be embellished with links to definitions and explanations but there is no strong evidence that this is significantly better than the paper and print equivalent. The reaction of many, if not most, students is to print out the material to refer to it in standard print form.

It is important to state that the learning resources to be discussed here are relevant for either problem-based learning or for lectures. This is part of its flexibility and versatility. Whilst there would appear to have been some swing in recent years towards problem-based learning in engineering courses in Australia, this is not uniform either in specific engineering faculties or in specific disciplines. The concern by some academics may be that problem-based learning, whilst satisfying some of the requirements of the ability to work in teams, to 
develop communication skills and to have an understanding of the societal, economic and environmental impacts of engineering decisions, it may not provide a deep and rigorous engineering foundation. In particular, it may be considered that it does not lay the necessary foundation for those students proceeding to research work. In a period of tight budget constraints it may be that self-learning and lifelong learning skills become more important than problem-based learning. The availability of carefully developed learning resources becomes most important.

Interactive resource material refers to courseware which allows a strong interaction with the user beyond the simple publishing of lecture notes in electronic form, even though as mentioned previously this may be done with imbedded material allowing the student to refer to background material, definitions, explanations etc. What are required are active components, such as animation, graphing and simulation in response to user inputs or choice of parameters.

The major interactive courseware in engineering mechanics in Australia would appear to be that of the group associated with Stone and Scott at the University of Western Australia. An example of such work can be found in Devenish et $\mathrm{al}^{4}$ for a module on work/energy and there described as a 'set of modules written in Hypercard incorporating stand alone animation programs that allow parameter variation and the observation of motion'. A further example of their work is their software for learning about curvilinear motion.

\section{The Interactive CD-Engineering Mechanics.}

The interactive courseware described in this paper is being developed at Monash University, Australia. The development work was funded through a Monash University Multi-media Grant to the Faculty of Engineering. The author is one of two academics providing academic content input, whilst the package design and production is being handled by multi-media consultants. The Engineering Faculty at Monash University introduced a new first year course in 1998 so it was an appropriate time to reconsider the learning and teaching resources for the first year subject Engineering Mechanics. Observation and feedback from the previous course in engineering mechanics, which was little different in topic content to the new course, was that student interaction with engineering equipment and hardware needed to be encouraged. Even though unlimited access was given to numerous perspex models of engineering devices, which the students had seen demonstrated on the overhead projector, and to actual mechanisms and gearing systems, there was only limited reaction from students to handle and experiment with them. Access was also given to computer presentations used in lectures and these were more used by students, who commented on the advantages of being able to view such presentations in their own time and at their own pace.

A decision was made to develop material that was suitable for lecture presentation but could equally be used by students as a learning resource and was more interactive than the previous computer presentations. Encouragement would still be given to handle real engineering hardware by making it freely accessible. The computer material would be able to be used by students at home as a stand alone product. The new material, made available for personal use by students through a CD-ROM. Contains 20 modules of engineering mechanics. The major topics, following a general and brief introduction to vector mechanics and fixed axis rotation, are mechanical systems and vibration, mechanisms, gears and gearing, and belt drives. The material can be navigated by selecting any lecture from the main menu which can be returned to at any time, then within each individual lecture by a topic page or via a topic popup menu. 
There are two possible modes of use, termed lecture mode and study mode. In lecture mode there is information build up in small blocks of information on each screen page, whilst study mode uses complete page by page viewing. Changing from one mode of viewing to the other is possible at any time. The modules were developed using Toolbook II, an authoring program to create educational software through interactive learning applications. In each lecture there is textual information, interactive exercises, illustrative animations, simulations and review questions. There is also the facility of using a personal notebook and access to a web page for course matters, solutions and contact to lecturing staff. The development has similarity to the work of Scott and Stone in the use of animation and simulation but differs in the scope of these simulations and directs them clearly to engineering. The modules of Scott and Stone are not engineering specific but could be used by science, particularly physics students.

\section{Exercises, Animations and Simulations.}

The following examples, Figure 1, offer some indication of the types of material contained in the twenty modules.

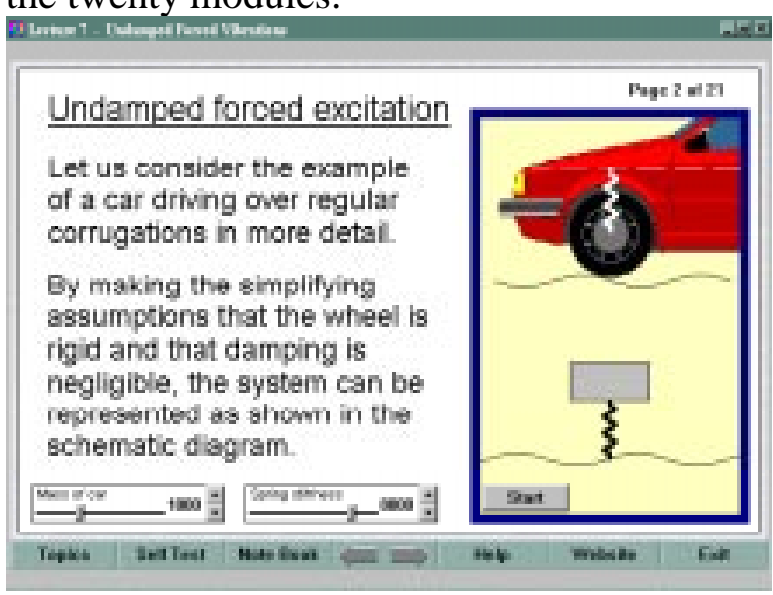

(a) Car Suspension Model

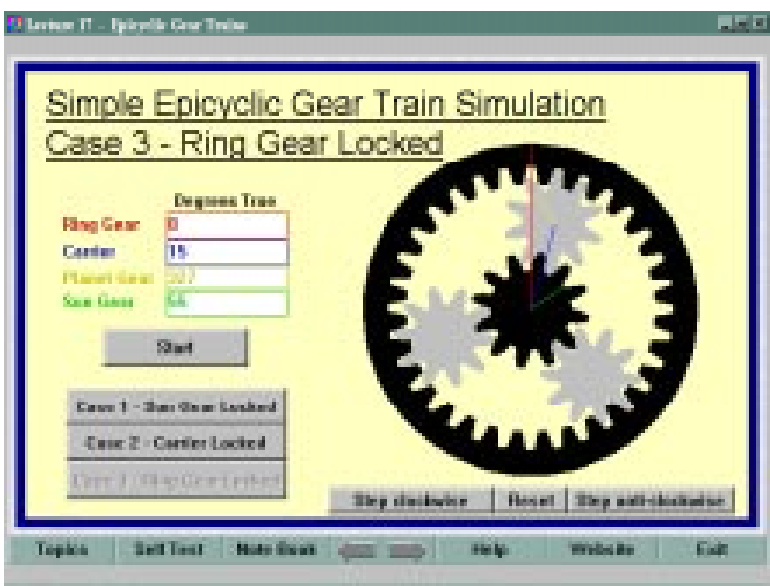

(d) Simple Epicyclic Gear Train

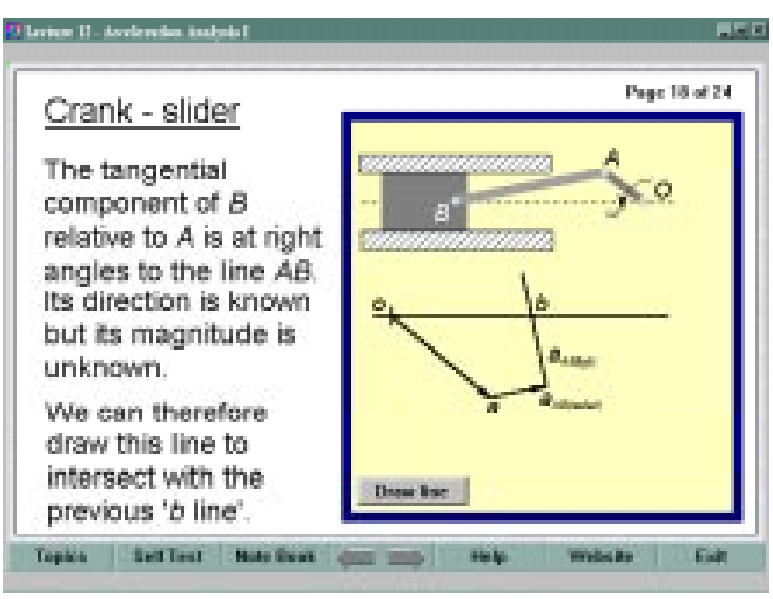

(b) Crank Slider Acceleration Model

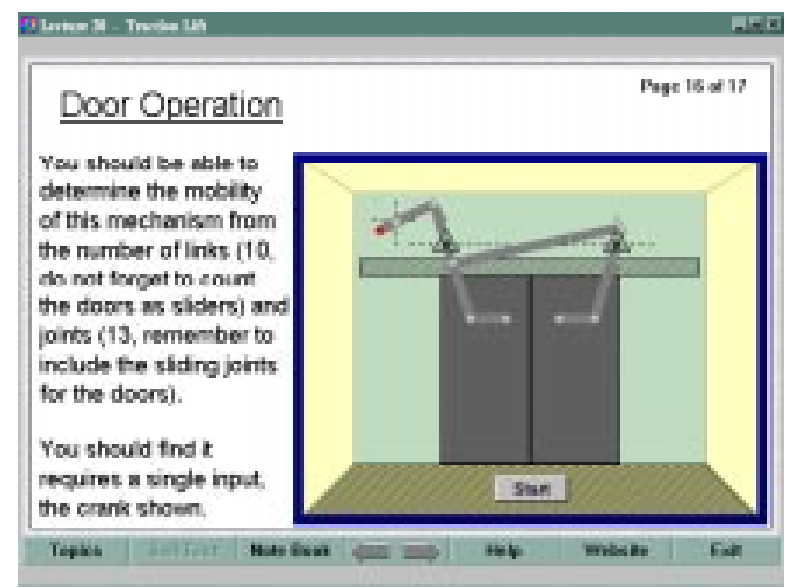

(d) Door Opening Mechanism

Figure 1. Some Examples

(a) Car Suspension Model - This is the simplest model of a car suspension on a harmonic road profile, damping being ignored. The simulation, which shows the motion of the mass based on the mathematical equations, allows students to change the car mass and/or spring stiffness then view the resulting motion. Whilst the model may be simple, 
particularly without damping, it has value as an early introduction to using mathematical models, because

- the model can be understood mathematically and the mathematical solution related to the physical motion emphasizing the physical relevance of the mathematical solution, thus allowing students to match mathematical solutions to the physical result,

- it gives an introduction to resonance effects and

- it can be related to the physical situation of a car on a corrugated road with the car shock absorbers out of action!

This model could be extended to include a shock absorber and further extended to a 2DOF model including tyre stiffness to make a more realistic model with a number of parameters that may be varied.

(a) Crank-Slider Acceleration Diagram - the student can work through the steps for drawing an acceleration diagram for a crank-slider mechanism. This frame is just one in a series of obtaining the acceleration diagram. When the velocity diagram is required to obtain particular velocities, it appears as a popup diagram.

(b) Simple Epicyclic Gear Train. This is an interactive exercise in which one of the three shafts (sun, carrier, ring) can be locked and the epicyclic train run or stepped through in a clockwise or anti-clockwise direction.

(c) Lift Door Operation- a mechanism that can be used for door opening. The mechanism can be operated either using the start button or turned using the mouse pointer on an active point of the crank.

\section{Relationship with Mathematical Packages and Laboratory Work.}

There have been significant changes in the mathematical and computer tools available for engineering mechanics from the analog computers in the 1960's, through digital simulation and computer programming from the 1970's onwards to the wide availability of mathematical and computer software of today. This availability often means that computer programming in languages such as FORTRAN, BASIC, PASCAL, C etc is no longer considered as much a necessity of engineering education. Rather, from the solution of differential equations to finite element analysis, students are exposed to application software with no need to develop their own application programs through self-programming. Clearly, without knowledge of the mathematical basis of the package, their use must be undertaken with care and an emphasis on the meaning and physical reality of the output.

There is little doubt that a solid understanding of engineering applications is based on a sound mathematical foundation. A lack of adequate mathematical ability is often a barrier to illprepared students. However, provided the student is exposed to, and understands, modelling, has an understanding of the physical reality of the mathematical solution and an ability to verify and apply solutions this can partly compensate for the lack of a deep mathematical preparation. In fact, much laborious and repetitive mathematics can now be avoided with the use of mathematical packages and consequently more realistic problems attempted. This is not to underplay the importance of mathematical ability but to handle the problem of less mathematically gifted students entering engineering.

The comments of $\operatorname{Sipcic}^{6}$ in his paper challengingly entitled 'What is Wrong with the Way we Teach Mechanics and how to Fix It' are worth noting. His view is that while students can 
solve carefully chosen problems they can not explain what their solutions mean. Further, their ability to transfer knowledge acquired to other engineering subjects is limited. His solution is to use the changes in technology to study problems that do not possess closed form solutions. The use of the interactive material in the package described in this paper may hopefully improve the relating by students of mathematical solutions to real engineering behaviour. A mathematical package can be used with the interactive material to broaden and extend the understanding gained from the simulations and the animations. In some simulations, the differential equations of the simulations may not be given or the solution detail obvious. This gap can be filled for the student through judicious use of a mathematical package.

Engineering students concentrating on computer applications cannot be isolated from the real practical world of engineering including their familiarity with engineering hardware and instrumentation. Whilst theoretical and computer studies provide understanding of theories and applications, students must be exposed to working and relating with engineering reality. For these reasons laboratory work, be it experimentation or familiarisation with equipment is important. The courseware described in this paper is coupled with experimentation and investigation of real systems including mechanisms and gearing.

\section{Conclusion}

The twenty modules of interactive material in this first year course on engineering mechanics should be a valuable teaching resource for staff and a valuable learning resource for students. The use of numerous interactive exercises involving parameter variation to produce quantitatively precise simulation and graphing, which can be viewed and reviewed by students in their own time, should lead to a better understanding of engineering mechanics.

\section{Acknowledgements}

The CD on Engineering Mechanics described in this paper was developed by the Quality Education at a Distance (QED) group at Monash University, comprising Brian Chapman, Anthony Fernando and Hugh Kelly. Robin Alfredson of the Department of Mechanical Engineering at Monash University aided the author in contributing content material.

\section{References}

1. Engineering Deans Council and Corporate Roundtable of the American Society for Engineering Education, Engineering Education for a Changing World, 1994.

2. Institution of Engineers, Australia, Changing the Culture: Engineering Education into the Future. Canberra: IEAust, 1996.

3. Berreen T \& Alfredson R, CD-Engineering Mechanics, QED Interactive Pty Ltd, Australia, 1998.

4. Devenish D G, Entwistle R D, Scott N and Stone B J, The teaching of work/energy to first year engineering students, Proc. $7^{\text {th }}$ AAEE Conf on Engng. Educ., Melbourne, Australia, 64-69, 1995.

5. Scott N \& Stone B J, The qualitative assessment of curvilinear motion, Proc. $7^{\text {th }}$ AAEE Conf. on Engng. Educ, Melbourne, Australia, 271-274, 1995.

6. Sipcic S R, What is Wrong With the Way We Teach Mechanics and How To Fix It, Proc. $4^{\text {th }}$ World Conf. on Engng. Educ. Saint Paul, USA, vol. 4. 8-20 1995.

TERRY BERREEN is a Professor in the Department of Mechanical Engineering at Monash University in Melbourne, Australia. He holds a PhD in mechanical Engineering and a degree in law. Currently he is the Secretary/Treasurer of the Australasian Association for Engineering Education and Editor of the Australasian Journal of Engineering Education. 